\title{
ARTICLE
}

\section{Genetic and phenotypic aspects of phenylalanine hydroxylase deficiency in Spain: molecular survey by regions}

\author{
LR D esviat ${ }^{1}, B$ Pérez ${ }^{1}, A$ Gámez ${ }^{1}, A$ Sánchez ${ }^{1}, M J$ G arcía ${ }^{1}, M$ M artínez-Pardo ${ }^{2}$, \\ C M archante ${ }^{3}$, D Bóveda ${ }^{4}, A$ Baldellou ${ }^{5}, J$ A rena $^{6}$, P Sanjurjo $^{7}$, A Fernández $^{8}$, \\ ML Cabello and M U garte ${ }^{1}$ \\ ${ }^{1}$ Centro de Biología M olecular 'Severo O choa' CSIC-UAM, U niversidad A utónoma, M adrid \\ ${ }^{2} \mathrm{H}$ ospital Ramón y Cajal, M adrid \\ ${ }^{3} \mathrm{H}$ ospital Virgen M acarena, Sevilla \\ ${ }^{4} \mathrm{H}$ ospital X eral de Galicia, Santiago de Compostela \\ ${ }^{5} \mathrm{H}$ ospital Infantil Miguel Servet, Zaragoza \\ ${ }^{6} \mathrm{H}$ ospital N uestra Señora de A ranzazu, San Sebastian \\ ${ }^{7} \mathrm{H}$ ospital de Cruces, Bilbao \\ ${ }^{8}$ Centro de Bioquímica y G enética Clínica, M urcia \\ ${ }^{9} \mathrm{H}$ ospital L a Fe, Valencia, Spain
}

\begin{abstract}
We present an extensive study of the genetic diversity of phenylalanine hydroxylase deficiency in the Spanish phenylketonuria population. We have analysed 195 PKU patients by DGGE analysis identifying 67 different mutations which represent $89 \%$ of the total mutant chromosomes. Seventeen mutations first described in Spain have not yet been detected elsewhere; ten of these are reported here for the first time. The clinical significance of this high genetic heterogeneity was examined by analysing the genotype-phenotype correlations, mainly focusing on the mild hyperphenylalaninaemia (M H P) phenotype. The genotypes found in a group of $93 \mathrm{M} \mathrm{H}$ P patients, the largest analysed so far, are described in detail, as well as the relative frequencies of the M H P mutations identified. From the total pool of mutations, 27 can be considered severe, 18 can be defined as mild and 13 as associated with M H P. The prevalent mutations correspond to one severe mutation (IV S10nt-11), one M H P mutation (A 403V) and two mild mutations (I65T and V 388M ). The high frequency of mutations with a low degree of severity can explain the relatively higher prevalence of MHP and mild PKU phenotypes in Spain compared with Northern E uropean populations. We have looked at the geographical distribution in Spain of the more common mutations, finding evidence of local mutation clustering, which could be the result of differences in the ethnic background and/or of genetic drift within each region.
\end{abstract}

Keywords: PKU mutations; geographic distribution; MHP genotypes; phenotype-genotype correlations

Correspondence: Magdalena U garte, Departamento de Biología Molecular, Centro de Biología Molecular 'Severo O choa' CSIC-UAM, U niversidad Autónoma, Campus de Cantoblanco, 28049 M adrid, Spain. Tel: 34917347011 ; Fax: 3491 7347797; E-mail: mugarte@cbm.uam.es

Received 30 October 1998; revised 4 December 1998; accepted 7 D ecember 1998 


\section{Introduction}

Mutations in the phenylalanine hydroxylase (PAH) gene are responsible for phenylketonuria (PKU), an autosomal recessive disorder that affects $1: 10000 \mathrm{Cau}$ casians. A s a consequence of the PA $H$ enzyme impairment, phenylalanine (Phe) accumulates in physiological fluids and, if left untreated, neurological damage occurs. The analysis of the molecular basis of PKU worldwide has led to the identification of more than 350 different PAH gene mutations which have been systematically compiled by the PA H M utation A nalysis Consortium (http://www.mcgill.ca/PA Hdb). The populations analysed present great variability in the mutational spectrum, according to their past genetic history. In Northern European populations, two mutations (IV S12nt1 and R 408W) account for $60 \%$ of the total PKU chromosomes, ${ }^{1}$ whilst in Southern European populations there is a greater genetic heterogeneity, eg in Spain, the three prevalent mutations (IVS10nt-11, I $65 \mathrm{~T}$ and $\mathrm{V} 388 \mathrm{M}$ ) are responsible for only $30 \%$ of the mutant alleles. ${ }^{2}$

The underlying genetic heterogeneity is the basis of the biochemical and clinical diversity of the disorder. It is now evident, from in vitro expression studies and from the increasing knowledge obtained in the study of the genotype-phenotype correlations, that the different mutations exert different effects on the PA $\mathrm{H}$ enzyme activity and stability, allowing prediction of the outcome in each patient depending on the combination of mutations present. A $n$ important issue derived from these results is the definition of M HP mutations which always confer the MHP phenotype, regardless of the mutation present on the other allele, which is particularly useful for distinguishing patients requiring dietary treatment from those who do not.

In previous studies of the Spanish PKU population 40 different mutations were detected after D G G E gene scanning of 129 mutant chromosomes. ${ }^{2}$ In this report we present an update on the spectrum of PKU mutations in the Spanish population from a study of 390 independent alleles. We have looked at the geographic backgrounds of the mutations in order to map the distribution of each PKU mutation in Spain. The examination of patients' phenotypes expands previous work, ${ }^{3}$ allowing estimation of the severity of most of the mutations detected. In particular, an extensive molecular study of $93 \mathrm{MHP}$ patients further delineates the genotypes responsible for this phenotype.

\section{Patients and Methods}

The study includes whole blood samples from 195 patients, referred to Madrid for genotype analysis, from different hospitals and follow-up centres in central Spain (mainly the $M$ adrid area), the north (B asque country), north-west ( $G$ alicia), south and east of Spain. In the analysis of the distribution of the PKU mutations, we have defined geographical subsets after investigating the origins of parents and grandparents, taking into account also the strong association between surnames and defined Spanish regions. In the central region of Spain we have included patients living in $M$ adrid but whose grandparents have different origins, as is the general rule in big capital cities, so as to define a geographical region representative of the overall demographic profile in Spain.

Patients were considered as having hyperphenylalaninaemia when the serum phenylalanine levels at diagnosis were higher than $120 \mu \mathrm{mol} / \mathrm{L}$ and after exclusion of a defect in tetrahydrobiopterin metabolism. A mong the patients, 28 $(14.4 \%)$ had classical PKU (tolerance $<400 \mathrm{mg}$ Phe/day), 16 $(8.3 \%)$ had moderate PKU (tolerance $400-500 \mathrm{mg}$ Phe/day), $41(21 \%)$ had mild PKU (tolerance $500-900 \mathrm{mg}$ Phe/day) and $93(47.6 \%)$ corresponded to mild hyperphenylalaninaemia (M H P, without dietary restriction), as defined previously. ${ }^{3}$ For 17 patients, most of them not compliant to diet or lost to follow-up, phenotype assignment was not possible.

G enomic DNA from patients and parents was extracted from whole blood using standard procedures. ${ }^{4}$ In some cases, PCR amplification was performed directly using dried blood spots as source of D NA. ${ }^{5}$ The 13 genomic fragments covering the entire coding region and splice junctions of the $\mathrm{PA} \mathrm{H}$ gene were amplified and analysed by simultaneous 'broad-range' DGGE ${ }^{6} \mathrm{~A}$ II fragments displaying an aberrant migrating band pattern in the DGGE gel were subjected to direct sequencing using the fmol sequencing kit (Promega, M adrid, Spain) and analysed on an automated DNA sequencer (ALF express, Pharmacia, Barcelona, Spain). When possible, the identified mutations were confirmed by restriction analysis (either directly or after creating the restriction site in the amplification, ACRS) of PCR products amplified again in affected subjects and their parents. The Mendelian inheritance was confirmed when parental samples were available by DGGE or restriction enzyme digestion.

In the estimation of mutation severity, after examining the observed phenotype for homozygous and functionally hemizygous patients, we have also taken into account the residual activity from those mutations expressed in vitro (data accessible at the PAH Mutation A nalysis Consortium web site, http://www.mcgill.ca/PAHdb) and the nature of the mutation, regarding stop, nonsense and splicing mutations as severe.

\section{Results}

\section{Mutational Spectrum}

In a previous study, 63PKU families representing 129 independent chromosomes were analysed by DGGE and direct sequencing. ${ }^{2}$ M ost of the families lived in M adrid, having diverse geographical origin due 
to immigration and admixture, and the sample was considered representative of the Spanish population. To validate and extend these results we have now incorporated into the $\mathrm{PAH}$ gene analysis patients from different follow-up centres in Spain. A total of 195 PKU patients have now been studied and we have increased the number of mutations detected from 40 to 67 (Figure 1), ten of them are novel. From the 67 identified mutations, 39 are disease causing, proved by in vitro expression or deduced from the nature of the mutation. The remaining mutations are unlikely to be neutral polymorphisms, following the criteria defined, ${ }^{7}$ although expression analysis is necessary to confirm this.

We have characterised $89 \%$ of the total mutant alleles. The four most frequent mutations (IV S10nt-11, A 403V, V 388M and I65T), with frequencies $<6 \%$, account for only $31 \%$ of the total PKU chromosomes. From the remaining mutations 39 are very rare, present only on one or two mutant chromosomes and the others have frequencies between $0.8-4.5 \%$.

\section{Novel Mutations}

The ten previously unreported mutations correspond to eight missense mutations (D 59Y, N 61K , E 76G, R 169H, R 176Q , P275R , A 313V , I 406T), one deletion causing a frameshift (G 352fsdelT) and one splicing mutation (IV S3nt-1) (Table 1). The N61K mutation was detected on two alleles from two heterozygous patients and the remaining mutations were present on one allele.

\section{Geographic Distribution}

We have examined the relative frequencies of the more common mutations in defined geographical subsets, the central region of Spain (mainly the Madrid area), Galicia (north-west Spain), A ndalusia (south Spain), and the Mediterranean area (east coast). A nother population subset within Spain with a clear ethnic origin, pre-Indoeuropean, are the Basques. ${ }^{8}$ H owever, PKU patients referred from the centres in the Basque

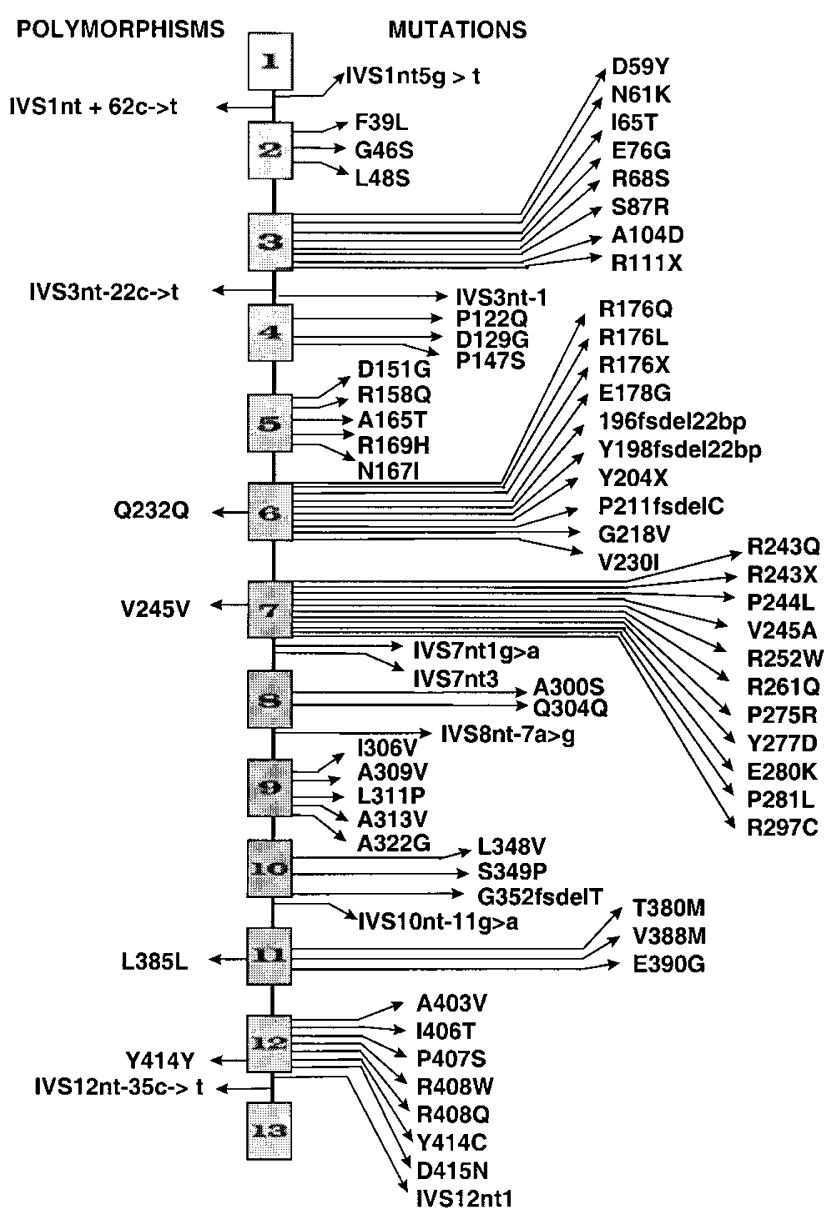

Figure 1 Schematic representation of the PA H gene with the location of the 67 mutations and 7 neutral polymorphisms detected in the Spanish PKU population

Table 1 Novel mutations identified in this study in Spanish PKU patients, showing the observed genotype-phenotype correlations

\begin{tabular}{|c|c|c|c|c|}
\hline M utation & Nucleotide change & Codon N/M & G enotypes & Phenotypes \\
\hline $\begin{array}{l}\text { D 59Y } \\
\text { N 61K }\end{array}$ & $\begin{array}{l}\mathrm{c} .175 \mathrm{G} \rightarrow \mathrm{T} \\
\mathrm{c} .183 \mathrm{C} \rightarrow \mathrm{G}\end{array}$ & $\begin{array}{l}\text { GAT/TAT } \\
\text { A A C/A A G }\end{array}$ & $\begin{array}{l}\text { D 59Y /A 403V } \\
\text { N 61K /IV S1nt5 } \\
\text { N 61K / R 176L }\end{array}$ & $\begin{array}{l}\text { MHP } \\
\text { MHP } \\
\text { MHP }\end{array}$ \\
\hline $\begin{array}{l}\text { E 76G } \\
\text { IV S3nt-1 } \\
\text { R 169H } \\
\text { R 176Q } \\
\text { P 275R } \\
\text { A 313V } \\
\text { G 352fsdelT } \\
\text { I 406T }\end{array}$ & $\begin{array}{l}c .227 \mathrm{~A} \rightarrow \mathrm{G} \\
\mathrm{c.} 353-1 \mathrm{~g} \rightarrow \mathrm{C} \\
\mathrm{c.} 506 \mathrm{G} \rightarrow \mathrm{A} \\
\mathrm{c} .527 \mathrm{G} \rightarrow \mathrm{A} \\
\mathrm{c} .824 \mathrm{C} \rightarrow \mathrm{G} \\
\mathrm{c.} 938 \mathrm{C} \rightarrow \mathrm{T} \\
\mathrm{c.} 1056 \mathrm{delT} \\
\text { c. } 1217 \mathrm{~T} \rightarrow \mathrm{C}\end{array}$ & $\begin{array}{l}\text { GA G/G G G } \\
353-1 \mathrm{~g} \rightarrow \mathrm{C} \\
\text { CGC/CAC } \\
\text { CGA /CA A } \\
\text { CCC/C G C } \\
\text { GCA /G TA } \\
1056 \mathrm{delT} \\
\text { ATA/A CA }\end{array}$ & $\begin{array}{l}\text { E 76G /P 122Q } \\
\text { IV S3nt-1/S349P } \\
\text { R 169H /P 281L } \\
\text { R 176Q /R 158Q } \\
\text { P 275R /L 348V } \\
\text { A 313V /nd } \\
\text { G 352fsdelT/I 306V } \\
\text { I 406T// 65T }\end{array}$ & $\begin{array}{l}\text { MHP } \\
\text { classic PKU } \\
\text { MHP } \\
\text { MHP } \\
\text { mild PKU } \\
\text { MHP } \\
\text { MHP } \\
\text { mild PKU }\end{array}$ \\
\hline
\end{tabular}

Nucleotide numbering starts at the ATG translation initiation codon, the corresponding G enB ank accession number is $U$ 49897; nd: not detected after DG GE analysis 
country had, in most cases, different origins and have been included in other geographical subsets. In the only patient with clear B asque ancestry, up to four generations, and a mild PKU phenotype, no mutations were found after DGGE and subsequent sequencing of the coding regions and known intronic sequences of the $\mathrm{PAH}$ gene.

When we analyse the Spanish PKU mutations by geographical region we observe a uniform distribution of IVS10nt-11, the prevalent mutation in Spain, but some of the other common mutations, although present overall, are clustered in specific regions (Table 2). Studies with less frequent mutations did not give any significant values (data not shown).

In G alicia, the predominant mutation (after IV S10nt11 ) is R 261Q , and the A $300 \mathrm{~S}$ mutation is also clustered in this region, with very few alleles found elsewhere. However, I65T and A 403V are clearly less frequent than in other regions, or compared with the overall frequency.

The Spanish subpopulation in the south of Spain (A ndalusia) has received influences from all the M editerranean cultures, as well as a strong A rab influence. We have found an extremely high frequency of A $403 \mathrm{~V}$ and $D 415 \mathrm{~N}$ mutations in this region (Table 2), which also reflects the predominating MHP phenotype present in this region (approximately $50 \%$ of the total cases). In contrast, the I65T mutation is not frequently detected here, and R $261 \mathrm{Q}$ is totally absent.

The $M$ editerranean subset, which has received influence from different M editerranean cultures (R omans, Greeks, Phoenicians), shows high frequencies of the mutations A 403V and R 243Q and a low frequency of V 388M .

As expected, in central Spain the mutation frequencies correspond largely to the overall frequencies. This probably reflects the heterogeneous origins of the population around a large capital city, due to immigration and admixture.

\section{Genotype-Phenotype Correlations: Mutation Severity}

D etailed genotype-phenotype correlations of the Spanish population have been documented elsewhere. ${ }^{3}$ The data recently obtained with the patients incorporated into this study further expand the pattern of associated phenotypes with each mutation, compiled by the PAH A nalysis Consortium D atabase (http://www.mcgill.ca/ PAH db). To date, 137 different genotypes have been identified in Spanish patients. From these, those cases corresponding to I65T or R $261 \mathrm{Q}$ combined with null mutations (functionally hemizygous patients), have no clear association with a single phenotype, confirming previous results. ${ }^{3,9,10}$ Thus, I65T combined with P281L results in classical PKU, but with S196fs or IV S7nt1 it results in moderate PKU, and with either IV S10nt-11 or $R 111 X$ it results in mild PKU. R 2610 with S196fs was found in a classic PKU patient, but it was also detected in moderate PKU patients combined with IVS10nt-11, R 408W or P281L. Both $165 T$ and R 261Q (25\% and $30 \%$ residual activity, respectively) combined with mild mutations always result in mild PKU. A nother mutation which associated with null mutations results in different phenotypes is R $176 \mathrm{~L}$. It is present always in MHP patients, even combined with IV S10nt-11, Y 204X or R 243X, but with Q304Q, a mutation presumably affecting splicing, it results in mild PKU. These cases represent the only inconsistencies in the genotypephenotype correlations in our population.

A fter examining the phenotype in homozygous and functionally hemizygous Spanish patients, and taking into account the nature of the mutation and the residual in vitro activity (available for 23 of the

Table 2 R elative frequencies of PKU mutations in geographical subsets within Spain

\begin{tabular}{|c|c|c|c|c|c|}
\hline \multirow[b]{2}{*}{ M utation } & $\begin{array}{l}\text { Central Spain } \\
\mathrm{n}=154\end{array}$ & $\begin{array}{l}\text { G alicia (north-west) } \\
\mathrm{n}=78\end{array}$ & $\begin{array}{l}\text { South of Spain } \\
n=96\end{array}$ & $\begin{array}{l}\text { M editerranean (east) } \\
n=40\end{array}$ & $\begin{array}{l}\text { O verall } \\
\mathrm{n}=390\end{array}$ \\
\hline & \multicolumn{5}{|c|}{ M utation frequency (\%) } \\
\hline IV S10 & 9 & 11.5 & 8.3 & 12.5 & 9.8 \\
\hline V 388M & 4.5 & 6.4 & 10.4 & 2.5 & 6.2 \\
\hline I65T & 9.5 & 3.8 & 3.1 & 10 & 6.7 \\
\hline A 403V & 7 & 1.3 & 14.6 & 12.5 & 8 \\
\hline R $261 Q$ & 2 & 10.3 & 0 & 5 & 4 \\
\hline R 243Q & 3.2 & 3.8 & 2 & 7.5 & 3.6 \\
\hline A 3005 & 0.6 & 6.4 & 1.2 & 0 & 1.8 \\
\hline D 415N & 3.2 & 0 & 7.3 & 0 & 3.3 \\
\hline Identified (\%) & 91 & 86 & 93 & 90 & 89 \\
\hline
\end{tabular}

n: number of alleles 
mutations present in Spain), we have deduced the mutation severity for 58 (86\%) of the mutations (Table 3). The prevalent mutations in Spain correspond to one severe mutation (IV S10nt-11), one M H P mutation (A 403V) and two mild mutations (I65T and $V 388 \mathrm{M})$. The estimation of the mutation severity coincides with results in other Caucasian populations. ${ }^{9-11}$

\section{MHP Patients}

We have studied the molecular basis of the MHP phenotype in 93 patients, defining 13 different mutations associated with MHP (Table 3 ). In this group of patients the prevalent MHP mutations are A 403V $(16.7 \%), R 176 \mathrm{~L}(8.6 \%)$ and D $415 \mathrm{~N}$ (6.5\%). T380M, A $300 \mathrm{~S}$ and $\mathrm{V} 230 \mathrm{l}$ are present in $5 \%, 3.7 \%$ and $3.2 \%$, respectively, of the alleles, and the remaining mutations have frequencies $<1.5 \%$.

In the MHP patients we have detected 68 different genotypes (Table 4), which correspond to combinations of

Table 3 Classification of PKU mutations detected in Spain, based on the estimation of their severity

\begin{tabular}{|c|c|c|c|}
\hline Severe & Mild & MHP & Undefined \\
\hline $\begin{array}{l}\text { IV S1nt5 } \\
\text { G 46S } \\
\text { IV S3nt-1 } \\
\text { R 111X } \\
\text { D 151G } \\
\text { A 165T } \\
\text { R 176X } \\
\text { S196fs } \\
\text { Y 198fs } \\
\text { Y 204X } \\
\text { P 211fsdelC } \\
\text { R 243X } \\
\text { R 252W } \\
\text { Y 277D } \\
\text { E 280K } \\
\text { P 281L } \\
\text { IV S7nt1 } \\
\text { IV S7nt3 } \\
\text { Q 304Q } \\
\text { IV S8nt-7 }_{\text {A 309V }} \\
\text { L 311P } \\
\text { S349P } \\
\text { G 352fs }_{\text {IV S10nt-11 }} \\
\text { R 408W }^{\text {a }} \\
\text { IV S12nt1 }^{\text {a }}\end{array}$ & $\begin{array}{l}F 39 L \\
I 65 T^{a} \\
\text { R 68S } \\
\text { A 104D } \\
\text { P 122Q } \\
\text { D 129G } \\
\text { R 158Q } \\
\text { N 167I } \\
\text { E 178G } \\
\text { G 218V } \\
\text { R 243Q } \\
\text { R } \\
\text { P 244L } \\
\text { R 261Q } \\
\text { L 348V } \\
\text { V 388M } \\
\text { P 407S } \\
\text { R 408Q } \\
\text { Y 414C }^{\text {a }}\end{array}$ & $\begin{array}{l}\text { N 61K } \\
\text { S87R } \\
\text { R 169H } \\
\text { R 176L } \\
\text { V 230I } \\
\text { V 245A } \\
\text { A 300S } \\
\text { I 306V } \\
\text { A 322G } \\
\text { T 380M } \\
\text { E 390G } \\
\text { A 403V } \\
\text { D 415N }\end{array}$ & $\begin{array}{l}\text { L 48S } \\
\text { D 59Y } \\
\text { E 76G } \\
\text { P 147S } \\
\text { R 176Q } \\
\text { P 275R } \\
\text { R 297C } \\
\text { A 313V } \\
\text { I 406T }\end{array}$ \\
\hline
\end{tabular}

amutations expressed in vitro
Table 4 G enotypes observed in Spanish M HP patients

\begin{tabular}{|c|c|c|c|}
\hline$\overline{\text { Allele } 1}$ & $\begin{array}{l}\mathrm{N} \text { ull } \\
\text { mutations }\end{array}$ & $\begin{array}{l}\text { A llele 2 } \\
\text { M issense } \\
\text { mutations }^{a}\end{array}$ & $\begin{array}{l}\text { M HP } \\
\text { mutations }\end{array}$ \\
\hline A 403V & $\begin{array}{l}\text { E 280K } \\
\text { IV S10nt-11 } \\
\text { IV S8nt-7 } \\
\text { R 111X } \\
\text { S349P }\end{array}$ & $\begin{array}{l}\text { R 68S } \\
\text { D 59Y } \\
\text { I 65T } \\
\text { G 218V } \\
\text { P 122Q } \\
\text { P 147S } \\
\text { E 178G } \\
\text { R 243Q } \\
\text { R 158Q } \\
\text { V 388M }\end{array}$ & $\begin{array}{l}\text { R 176L } \\
\text { A 300S } \\
\text { A 403V }\end{array}$ \\
\hline R 176L & $\begin{array}{l}\text { IV S10nt-11 } \\
\text { R 243X } \\
\text { Y 204X } \\
\text { P281L }\end{array}$ & $\begin{array}{l}\text { R 243Q } \\
\text { R 261Q } \\
\text { V 388M } \\
\text { Y 414C }\end{array}$ & $\begin{array}{l}\text { D 415N } \\
\text { E 390G } \\
\text { N 61K } \\
\text { A 403V }\end{array}$ \\
\hline D 415N & $\begin{array}{l}\text { E 280K } \\
\text { IV S10nt-11 } \\
\text { R 243X } \\
\text { S349P }\end{array}$ & $\begin{array}{l}\text { I65T } \\
\text { L 348V } \\
\text { R 261Q } \\
\text { V 388M }\end{array}$ & $\begin{array}{l}\text { R 176L } \\
\text { T380M }\end{array}$ \\
\hline T 380M & IV SInt5 & $\begin{array}{l}\text { I } 65 T \\
\text { R 243Q }\end{array}$ & $\begin{array}{l}\text { T380M } \\
\text { A 300S } \\
\text { D 415N }\end{array}$ \\
\hline V 230I & $\begin{array}{l}\text { IV S10nt-11 } \\
\text { L 311P } \\
\text { R 158Q } \\
\text { Y 198fs }\end{array}$ & V 388M & \\
\hline A $300 \mathrm{~S}$ & & $\begin{array}{l}\text { I } 65 \mathrm{~T} \\
\mathrm{R} 243 \mathrm{Q} \\
\mathrm{V} 388 \mathrm{M}\end{array}$ & $\begin{array}{l}\text { A } 403 \mathrm{~V} \\
\text { T380M }\end{array}$ \\
\hline V 245A & $\begin{array}{l}\text { IV S1nt5 } \\
\text { R 243X }\end{array}$ & R 243Q & \\
\hline $\begin{array}{l}\text { E 390G } \\
\text { S87R } \\
\text { N 61K } \\
\text { R 169H } \\
\text { A 322G } \\
\text { I 306V }\end{array}$ & $\begin{array}{l}\text { IV S12nt1 } \\
\text { IV S10nt-11 } \\
\text { IV S1nt5 } \\
\text { P281L } \\
\text { P211fsdelC } \\
\text { G 352fsdelT }\end{array}$ & & R 176L \\
\hline $\begin{array}{l}\text { E 76G } \\
\text { R 176Q } \\
\text { V 388M }\end{array}$ & & $\begin{array}{l}\text { P 122Q } \\
\text { R 158Q } \\
\text { N 167I } \\
\text { R 68S }\end{array}$ & \\
\hline
\end{tabular}

corresponding to either mild mutations or mutations of undefined severity, see Table 3.

a) a MHP mutation with either a severe or a mild mutation,

b) two MHP mutations, or

c) two mild mutations.

In the course of this study, four individuals with very slight hyperphenylalaninaemia $(125-180 \mu \mathrm{m})$ were referred to us for genetic analysis. DGGE gene scanning ruled out any mutations in the coding and adjacent intronic regions of the PAH gene, finally discarding a PAH deficiency. 


\section{Discussion}

A total of 390 independent Spanish PKU chromosomes has been found to carry 67 different mutations, among them 17 are at present unique to our population and 10 of them are described here for the first time. Increasing the number of analysed alleles with respect to earlier studies has resulted in the detection (on one or two alleles) of mutations prevalent in Northern Europe (IVS12nt1 and R 408W) and which were considered before to be totally absent in our population. ${ }^{2}$ In this update on the spectrum of PKU mutations in Spain, there is a significant increase ( $8 \%$ versus $3.1 \%$ ) in the relative frequency of A 403V respect to earlier studies, where the MHP phenotype was under-represented in the total patient sample. In the present work, $47.6 \%$ of the analysed patients exhibit the MHP phenotype, more in agreement with the pattern of phenotype distribution observed in Spain (according to the 1996 census of the $\mathrm{N}$ ational Screening Programme, 54\% of the total positive cases, 1:9500, corresponded to MHP patients). A 403V appears now as the second most frequent mutation in Spain (8\%), after IVS10nt-11 $(10 \%)$. The relative frequencies of the remaining mutations basically resemble those previously described. $^{2}$

O verall, the sample of 195 patients analysed by DGGE represents different geographical subsets, ascertained by genealogical studies and origin of the surnames, which are related to specific regions of Spain. Patients in central Spain ( $M$ adrid area) represent all the different regions, corroborated by the similarities in the mutation distribution of this sample and the total one. In the remaining geographical subsets (Table2), we observe patterns of mutation clustering, as has been reported for $\mathrm{CF}^{12}{ }^{12}$ In particular, in G alicia there was an unexpected distribution of CFTR alleles, analogous to what we have observed in the study of PKU mutations. This is probably due to genetic drift and the relative isolation of this population, both geographically and migrationally (practically no immigration). A lthough $G$ alicia seems to have received Celtic influences from the North A tlantic coast during the first millennium $B C$, the present study reveals a lower frequency in this region of $165 T$, a mutation of proposed Celtic origin. ${ }^{13}$ A recent analysis of $m t D N A$ of the $G$ alician population demonstrates that the referred contact with the Celts had little demographic effect and places Galicians at the genetic edge of E uropean variation. ${ }^{14}$

It can be assumed that the clustering of $\mathrm{R} 261 \mathrm{Q}$ mutation in Galicia and in other regions ${ }^{15,16}$ is caused by a local increase through genetic drift. In Portugal, R $261 \mathrm{Q}$ is the second most frequent mutation (10.4\% ), ${ }^{17}$ which could also account for its elevated frequency in Galicia, geographically close.

A t present, genetic differences tend to disappear with migration and admixture between regions. However, stratification of PK U mutations is evident in Spain and in other countries, ${ }^{18-20}$ reflecting the maintenance of population subsets. In this way, the various demographic histories of the Spanish population may account for the non-uniform distribution of PKU mutations other than IV S10nt-11.

In the analysis of the genotype-phenotype correlations we have used functionally hemizygous genotypes to evaluate the effect of missense alleles. O ur findings have clinical relevance, as the estimation of the severity of most of the mutations in Spain confirm data from other populations, ${ }^{9-11}$ allowing an increasingly reliable prediction of the biochemical phenotype. In the case of $165 T$ and R261Q, it is worth noting that, when expressed in vitro, these two mutations as well as others for which discordant genotype-phenotype associations have been referred (V 388M , Y 414C, R 158Q), all show immunoreactive protein. In medium chain acyl-CoA (MCAD) deficiency, the amount of stable mutant protein and the residual activity can be modulated changing the cultivation temperature and the levels of chaperonines, providing clues to explain the variable phenotypical manifestations of the disorder. ${ }^{21,22}$ In PKU, where most expression studies have shown decreased stability of the mutant proteins, such mechanisms involving the protein quality control system ${ }^{23}$ could also underlie the variable phenotypic expression of unstable mutant PA $\mathrm{H}$ proteins.

The high frequency of mutations with a low degree of severity can explain the relatively higher prevalence of MHP and mild PKU phenotypes in Spain compared with Northern European populations. In this work we detail the genotypes found in a group of $93 \mathrm{MHP}$ patients, the largest analysed so far. O verall, there are 13 mutations which are unambiguously associated with the MHP phenotype (Table 3). The pattern of MHP mutations, with a prevalence of A $403 \mathrm{~V}(16.7 \%)$, differs from that in other populations; in Denmark the predominant MHP mutation is $\mathrm{D} 415 \mathrm{~N},{ }^{24}$ in Sicily the highest frequency corresponds to $\mathrm{A} 300 \mathrm{~S}^{11}$ and in I reland to T380M. ${ }^{25}$

In the course of this study, four patients were found to present no mutations in the analysed regions of the $\mathrm{PAH}$ gene. A lthough mutations elsewhere in the gene 
could not be definitely ruled out, a PAH deficiency was finally discarded, considering that the phenylalanine levels were borderline (125-180 $\mu \mathrm{m})$ with the generally accepted threshold for dietary intervention. This extends the usefulness of DGGE analysis to distinguish patients with phenylalanine levels close to the cut-off from the normal range.

A lthough one might suppose, in view of the multiple mutations identified at present in the PAH gene, that the detection of novel mutations is becoming rare, it is evident that in the total pool of PKU chromosomes there is a very high number of rare mutations which are being discovered progressively as more alleles are studied worldwide.

\section{Acknowledgements}

Part of this work was supported by a grant from the Comunidad A utónoma de M adrid (08.6/0006/98). The institutional grant of 'Fundación Ramón A reces' to the Centro de Biología Molecular 'Severo Ochoa' is gratefully acknowledged.

\section{References}

1 G uldberg $\mathrm{P}$, Henriksen KF, G üttler $\mathrm{F}$ : M olecular analysis of phenylketonuria in Denmark: $99 \%$ of the mutations detected by Denaturing Gradient Gel Electrophoresis. G enomics 1993; 17: 141-146.

2 Pérez $B$, D esviat $L R, U$ garte $M$ : A nalysis of the phenylalanine hydroxylase gene in the Spanish population: mutation profile and association with intragenic polymorphic markers. A m J H um G enet 1997; 60: 95-102.

3 Desviat LR, Pérez B, García MJ et al: Relationship between mutation genotype and biochemical phenotype in a heterogeneous Spanish phenylketonuria population. Eur J H um G enet 1997; 5: 196-202.

4 John SWM, Weitzner G, Rozen R, Sciver CR: A rapid procedure for extracting genomic DNA from leukocytes. N ucleic A cids Res 1991; 19: 408.

5 Pérez $B, D$ esviat $L R, D$ íe $M$ et al: Presence of the Mediterranean PKU mutation IVS10 in Latin A merica. H um M ol G enet 1993; 2: 1289-1290.

6 Guldberg P, G üttler F: 'B road-range' DGGE for singlestep mutation scanning of entire genes: application to human phenylalanine hydroxylase gene. N ucleic A cids Res 1993; 22: 880-881.

7 Cotton RGH, Scriver CR: Proof of 'disease causing' mutation. H um M utat 1998; 12: 1-3.

8 Cavalli-Sforza $L L$, Piazza A : H uman genomic diversity in Europe: a summary of recent research and prospects for the future. E ur J H um G enet 1993; 1: 3-18.

9 Kayaalp E, Treacy E, Waters PJ, Byck S, Nowacki $P$, Scriver CR: H uman phenylalanine hydroxylase mutations and hyperphenylalaninemia phenotypes: a metanalysis of genotype-phenotype correlations. A m J H um G enet 1996; 61: 1309-1317.
10 Guldberg P, Rey F, Zschocke J et al: A European multicenter study of phenylalanine hydroxylase deficiency: classification of 105 mutations and a general system for genotype-based prediction of metabolic phenotype. A m J H um G enet 1998; 63: 71-79.

11 R omano V, G uldberg P, G üttler F et al: PA H deficiency in Italy: correlation of genotype with phenotype in the Sicilian population. I I nher M etab D is 1996; 19: 15-24.

12 Chillón $M$, Casals T, Giménez J et al: A nalysis of the CFTR gene confirms the high heterogeneity of the Spanish population: 43 mutations account for only $78 \%$ of CF chromosomes. H um G enet 1994; 93: 447-451.

13 Treacy E, Byck S, Clow S, Scriver CR: 'Celtic' phenylketonuria chromosomes found? Evidence in two regions of Q uebec province. E ur J H um G enet 1993; 1: 220-228.

14 Salas A, Comas D, Lareu MV, Bertranpetit J, Carracedo $A$ : mtDNA analysis of the Galician population: a genetic edge of European variation. Eur J H um Genet 1998; 6: 365-375.

15 Eisensmith RC, Okano $Y$, Dasovich $M$ et al: Multiple origins for phenylketonuria in $\mathrm{E}$ urope. A $\mathrm{m}$ J H um G enet 1992; 51: 1355-1365.

16 Guzzetta V, B onapace G, Dianzani I et al: Phenylketonuria in Italy: distinct distribution pattern of three mutations of the phenylalanine hydroxylase gene. J Inherit M etab D is 1997; 20: 619-624.

17 Rivera I, Leandro P, Lichter-Konecki $U$, Tavares de A Imeida I, Lechner MC: Population genetics of hyperphenylalaninaemia resulting from phenylalanine hydroxylase deficiency in Portugal. J Med Genet 1998; 35: 301-304.

18 Eiken HG, Knappskog PM, Boman $\mathrm{H}$ et al: Relative frequency, heterogeneity and geographic clustering of PKU mutations in Norway. Eur J Hum Genet 1996; 4: 205-213.

19 Tyfield LA, Stephenson A, Cokburn F et al: Sequence variation at the phenylalanine hydroxylase gene in the B ritish Isles. A m J H um G enet 1997; 60: 388-396.

20 Carter KC, Byck S, Waters PJ et al: Mutation at the phenylalanine hydroxylase gene and its use to document population genetic variation: the Q uebec experience. E ur J H um G enet 1998; 6: 61-70.

21 Bross $P$, Jespersen $C$, Jensen TG et al: $E$ ffects of two mutations detected in medium-chain acyl-COA dehydrogenase (MCAD) deficient patients on folding, oligomer assembly and stability of MCAD enzyme. J Biol Chem 1995; 270: 10284-10290.

22 A ndresen BS, Bross $P, U$ dvari $S$ et al: The molecular basis of medium-chain acyl-C OA dehydrogenase (MCA D) deficiency in compound patients: is there correlation between genotype and phenotype?. Hum Mol Genet 1997; 6: 695-707.

23 Gottesman S, Wickner S, Maurizi MR: Protein quality control: triage by chaperones and proteases. $G$ enes $D$ ev 1997; 11: 815-823.

24 Guldberg P, Henriksen KF, Thony B, Blau N, G üttler F: Molecular heterogeneity of nonphenylketonuria hyperphenylalaninemia in 25 D anish patients. G enomics 1994; 21: 453-455.

25 Zschocke J, Graham CA, Stewart FJ, Carson DJ, Nevin NC: Non-phenylketonuria hyperphenylalaninemia in $\mathrm{N}$ orthern I reland: frequent mutation allows screening and early diagnosis. H um M utat 1994; 4: 114-118. 